\title{
Covid-19 Pandemic: Need to Exercise Caution While Using Hypochlorite Sanitizer in Manufacturing Industries
}

\author{
S. K. Bhaumik
}

Submitted: 2 November 2020/Accepted: 5 November 2020/Published online: 21 November 2020

(C) ASM International 2020

\begin{abstract}
World is fighting Covid-19 pandemic since beginning of the year 2020. To prevent spread of Covid-19 disease, sanitization of workplaces using sodium hypochlorite $(\mathrm{NaOCl})$ disinfectant is one of the several precautionary steps that are followed currently. In this letter, I share an experience wherein regular spraying of $\mathrm{NaOCl}$ solution in metal forming section of an organization led to development of corrosion damage and rejection of a large number of aircraft structural components made of Al2024 alloy sheet material.
\end{abstract}

Keywords Covid-19 $\cdot$ Sanitization $\cdot \mathrm{NaOCl}$ solution

\section{Introduction}

World Health Organization (WHO) announced the outbreak of coronavirus disease 2019 (Covid-19) as public health emergency of international concern in January 2020 and subsequently declared it as pandemic in March 2020. It has been the deadliest pandemic that the mankind has seen since the Spanish flue a century ago in 1918. As per WHO, "Covid-19 disease spreads primarily from person to person through small droplets from the nose or mouth, when a person with COVID-19 coughs, sneezes, or speaks" [1]. These droplets remain suspended in air for some time and finally land on the surfaces/objects. People in the vicinity who inhale these droplets or touch the surfaces and then touch their nose, eyes, or mouth can get infected with the

S. K. Bhaumik ( $\square)$

Materials Science Division, National Aerospace Laboratories,

Council of Scientific and Industrial Research (CSIR),

Bangalore 560017, India

e-mail: subir@nal.res.in virus. The pandemic is ongoing, and as of October 27, 2020, more than 43 million people got infected globally with a death toll of over 1.1 million.

Soon after the declaration of Covid-19 pandemic, WHO came up with various guidelines as preventive measures and to contain community transmission of virus. The recommendations included frequent washing of hands with soap solution, wearing face mask, maintaining physical distancing, etc. As in all pandemics, the immediate effect of outbreak of the disease was uncontrollable, and hence, countries after countries announced travel restrictions and imposed complete lockdowns ranging from a couple of weeks to several weeks. The lockdowns had very serious and adverse impact on economy and livelihood, and hence, they were lifted in most of the countries in a phased manner with specific guidelines such as reduced workforce strength, staggered working time, and protocol for dealing with Covid-19 patients to be followed in workplaces. Majority of these guidelines issued by the Governments were for avoidance of gathering and maintenance of physical distancing while the basic preventive measures for individuals recommended by WHO remained unaltered over the last 10 months. One of the mandatory guidelines for industries/establishments/institutions was periodic sanitization of the workplaces. Although WHO recommended a number of disinfectants depending on various factors/ application areas, dilute aqueous solution of sodium hypochlorite $(\mathrm{NaOCl})$ with concentrations ranging from $0.1 \%(1000 \mathrm{ppm})$ to $0.5 \%(5000 \mathrm{ppm})$ has been one of the commonly used disinfectants in workplaces and offices. While in organizations/establishments, authorities/administrators ensured/recommended preventive actions for the spread of Covid-19 in workplaces, certain fundamental aspects were often overlooked, especially with reference to chemical reaction of metals and alloys in contact with the 
sanitizer solutions. In this note, I share a recent experience on how indiscriminate use of disinfectants in workplaces can be disastrous at times.

\section{The Incidence}

In an organization, there was rejection of unusually large number of aircraft components made of cladded 2024 Alalloy sheet material. The components were fabricated by sheet metal forming process, and they were subjected to dye penetrant inspection (DPI) as per the standard operating procedure laid down in the manufacturing process schedule. This inspection was meant for checking whether or not the components developed any cracks during the forming process. In this particular case, after DPI, the inspector cited presence of surface defects on the components as the basis for rejection. A few such components were submitted to laboratory for investigation (Fig. 1a). Examination of the defective areas revealed that the surface defects observed by the inspector were nothing but corrosion pits (Fig. 1b). Further study was undertaken to identify the source of corrosion damage to the components. It was informed that the components were sent for inspection within a couple of days' time after the fabrication. Hence, there was suspicion that probably, the Al-alloy sheet material itself had surface defects in the form of pitting corrosion. Metallurgical examination revealed that indeed the starting raw material, that is, the cladded Al-alloy sheets had corrosion pits similar to those noticed on the fabricated components. Figure 2 shows the appearance of a typical sheet surface. In situ composition analysis showed that the corrosion products contained sodium $(\mathrm{Na})$ and chlorine $(\mathrm{Cl})$ in high concentrations (Table 1). Corrosion pits were also observed on all the sheets that were kept in the sheet metal forming shop. This raised serious concern since the material was procured in recent times from a reputed aerospace material supplier. The sheets were supplied with surface protective film and certificate of confirmation. In the input material inspection note, there was no mention of any surface abnormalities on the sheet material. Therefore, severe damages to the material by corrosion in a short span of time in a relatively dry atmosphere were unexplainable at that moment. Later, it was discovered that as a general precaution for containing Covid-19, metal forming shop where the Al-alloy sheet material was kept was sanitized at least twice a day by spraying aqueous $\mathrm{NaOCl}$ solution with concentration of $0.1-0.5 \%$.

It is well known that $\mathrm{NaOCl}$ hydrolyzes in water and the following reaction occurs:

$$
\begin{aligned}
\mathrm{NaOCl}+\mathrm{H}_{2} \mathrm{O} & \leftrightarrow \mathrm{NaOH}+\mathrm{HOCl} \\
& \leftrightarrow \mathrm{Na}^{+}+\mathrm{OH}^{-}+\mathrm{H}^{+}+\mathrm{OCl}^{-}
\end{aligned}
$$

Further, under certain conditions, hypochlorite anion dissociates to form chloride ions and oxygen gas.

$$
2 \mathrm{OCl}^{-} \rightarrow 2 \mathrm{Cl}^{-}+\mathrm{O}_{2}(\mathrm{~g})
$$

In general, Al-alloys exhibit corrosion resistance in a wide range of environments due to the presence of protective, passive oxide on the surface. However, in environments that contain $\mathrm{NaOH}$ and aggressive anions such as chloride, $\mathrm{Cl}^{-}$, the passive film becomes unstable and degrades locally causing film breakdown and pitting corrosion [2]. Hence, the reason for corrosion damage to the Al-alloy sheet material in the present case could be identified. Following this investigation, it was recommended not to use hypochlorite containing disinfectants in workplaces dealing with processing/storage of metals and alloys.
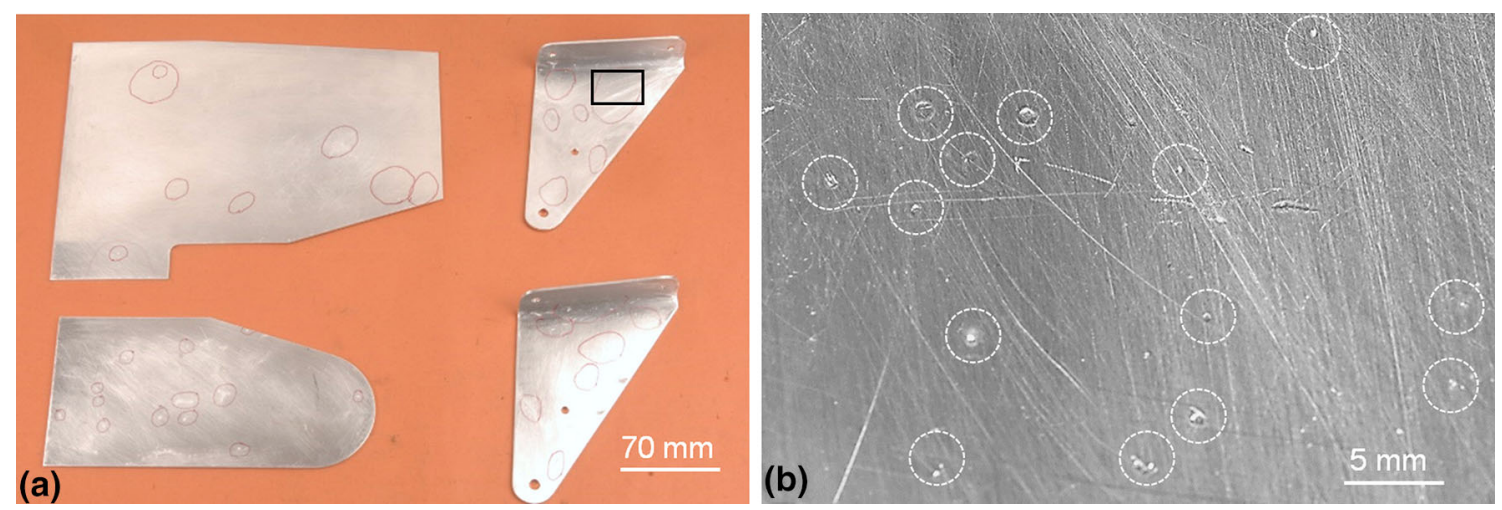

Fig. 1 (a) A few 2024 Al-alloy sheet metal components rejected after DPI and (b) close-up view of the region marked in (a) showing corrosion pits (encircled) 

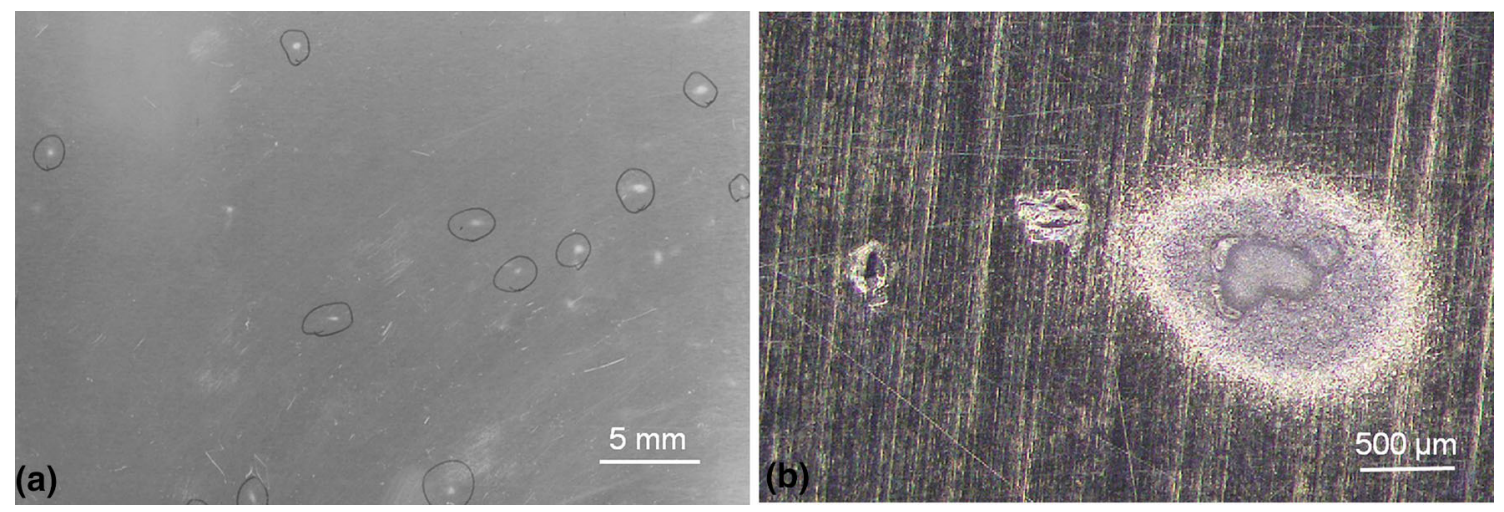

Fig. 2 (a) An affected region on the cladded 2024 Al-alloy sheet surface showing presence of corrosion pits (encircled) and (b) a typical corrosion pit as seen under a stereo-binocular microscope

Table 1 Results of semi-quantitative composition analysis of the corrosion products; analysis carried out using energy-dispersive $\mathrm{x}$-ray (EDX) analyzer attached to a scanning electron microscope

\begin{tabular}{llcl}
\hline & \multicolumn{3}{c}{ Composition, wt.\% } \\
\cline { 2 - 4 } Elements & 2024 Al-alloy & Corrosion pit 1 & Corrosion pit 2 \\
\hline $\mathrm{O}$ & - & 25.6 & 16.1 \\
$\mathrm{Na}$ & & 6.4 & 1.9 \\
$\mathrm{Mg}$ & $1.2-1.8$ & 1.0 & 1.1 \\
$\mathrm{Si}$ & $0.5 \max$ & 0.8 & 2.8 \\
$\mathrm{Cl}$ & - & 3.4 & 3.3 \\
$\mathrm{~K}$ & - & 0.8 & 0.6 \\
$\mathrm{Ca}$ & - & 1.5 & 1.1 \\
$\mathrm{Fe}$ & 0.5 max & - & - \\
$\mathrm{Cu}$ & $3.8-4.9$ & 0.1 & 0.2 \\
$\mathrm{Mn}$ & $0.3-0.9$ & - & - \\
$\mathrm{Al}$ & Balance & Balance & Balance \\
\hline
\end{tabular}

\section{Summary}

From the incident cited in this letter, it is evident that while the Government advisory on sanitization of workplaces was followed meticulously to prevent spread of Covid-19, no attention was paid to examine the possible chemical effect of $\mathrm{NaOCl}$ disinfectant on metals and alloys. It is important to note that hypochlorite solution can cause corrosion damage to most metals and alloys that are commonly used in manufacturing industries. Hence, selection of disinfectants for sanitizing such workplaces should be done judiciously and after thorough examination/ evaluation. Otherwise, the consequential corrosion damages to raw materials as well as machineries can be very severe and beyond repair leading to not only wasteful work and economic losses, but also delays in delivery schedules of production firms.

\section{References}

1. World Health Organization, http://www.who.int

2. S.D. Cramer, B.S. Covino Jr. (eds.), Corrosion: Environments and Industries, ASM Handbook, vol. 13C (ASM International, Metals Park, 2006), pp. 616-620

Publisher's Note Springer Nature remains neutral with regard to jurisdictional claims in published maps and institutional affiliations. 